Prospective Assessment

\title{
e Comparison of High-Viscosity Cement Vertebroplasty and Balloon Kyphoplasty for the Treatment of Osteoporotic Vertebral Compression Fractures
}

Cheng-hu Wang, MD ${ }^{1,2}$, Jin-zhu Ma, MD², Chuan-chen Zhang MD, $\mathrm{PhD}^{3}$, and Lin Nie, MD, PhD ${ }^{1}$

From: ${ }^{1}$ Department of Spine Surgery, Qilu Hospital, Shandong University, P.R. China; 2Department of Orthopedics, Liaocheng People's Hospital,

P.R. China; ${ }^{3}$ Department of Radiology, Liaocheng People's Hospital, Liaocheng, P.R. China

Address Correspondence: Lin Nie, MD, PhD Department of Spine Surgerys Qilu Hospital

Shandong University, No.44 Wenhua Xi Road, Jinan, 250012,

P.R. China

E-mail:

hugo_nie@hotmail.com

Disclaimer: There was no external funding in the preparation of this manuscript. Conflict of interest: Each author certifies that he or she, or a member of his or her immediate

family, has no commercial association (i.e., consultancies, stock ownership, equity interest, patent/licensing arrangements, etc.) that might pose a conflict of interest in connection with the submitted manuscript.

Manuscript received: 06-26-2014 Revised manuscript received: o9-30-2014 Accepted for publication: 11-5-2014

Free full manuscript: www.painphysicianjournal.com
Background: Percutaneous vertebroplasty is a widely used vertebral augmentation procedure for treating osteoporotic vertebral compression fractures (OVCFs). But high cement leakage rate caused by a low-viscosity cement and high injection pressure has limited its general use. Balloon kyphoplasty (BKP) and high-viscosity cement vertebroplasty (HVCV) are 2 modifications of vertebroplasty designed to decrease cement leakage.

Objective: To assess the safety and efficacy of HVCV compared with BKP.

Study Design: A prospective cohort study.

Setting: Department of Spine Surgery, an affiliated hospital of a medical university.

Method: One hundred seven patients suffering from painful OVCFs were randomly assigned into HVCV or BKP groups. Visual Analog Scale (VAS), Oswestry Disability Index (ODI), cement leakage, and vertebral height restoration were evaluated. All occurring complications and injected cement volumes were recorded. The follow-up time was one year.

Results: VAS and ODI scores improved in both groups, and did not differ significantly between the 2 groups. More cement was used in the BKP group than in HVCV group (4.22 vs. 3.31 $\mathrm{mL}, P<0.0001)$. The incidence of cement leakage in the HVCV group was lower than that of the BKP group (13.24\% vs $30.56 \%, P<0.05)$. No symptomatic cement leakages occurred in the HVCV group. In the BKP group, one patient experienced discogenic back pain related to a disc leak, and another patient had asymptomatic cement emboli in the lung related to venous leakage. The mean compression rate before the procedure was $29.98 \%$ in the HVCV group and $28.67 \%$ in the BKP group $(P=0.94)$. The vertebral height was improved significantly and maintained at one-year follow-up in both groups. BKP was more effective in vertebral height restoration than HVCV $(44.87 \%$ vs. $23.93 \%, P<0.0001)$. There was one case of a new adjacent vertebral fracture in the HVCV group (2\%), and 4 cases of new nonadjacent vertebral fractures in the BKP group (7.84\%) $(P=0.18)$.

Limitations: A single-center and relatively small-sample size study.

Conclusion: HVCV and BKP are safe and effective in improving quality of life and relieving pain. HVCV has a lower cement leakage rate, whereas BKP is more effective in vertebral height restoration. Subsequent fractures are not different between the 2 groups.

Key words: Vertebral compression fracture, spine, osteoporosis, cement augmentation, balloon kyphoplasty, vertebroplasty, cement leakage

Pain Physician 2015; 18:E187-E194 
D) ercutaneous vertebroplasty is a widely used vertebral augmentation procedure (VAP) for treating painful osteoporotic vertebral compression fractures (OVCFs) when conventional therapies are not effective. Vertebroplasty consists of injecting a low viscosity cement into a collapsed vertebra in order to reinforce the fractured vertebra and gain pain relief. Numerous reports have indicated significant pain relief after this procedure, but using a low-viscosity cement and injecting cement at a high pressure result in more cement leakage (1). Balloon kyphoplasty (BKP) is a modification of vertebroplasty. During a BKP procedure, an inflatable balloon is inserted into a collapsed vertebral body. Once inflated, the balloon elevates the endplates and creates a cavity. Then the cement is injected at a low pressure into the cavity of the collapsed vertebral body. Injecting cement into a cavity under low pressure reduces the risk of cement leakage.

Cement viscosity is considered as another critical factor in controlling cement leakage (2). Baroud et al (3) in their experimental model demonstrated cement leakage was reduced from more than $50 \%$ to less than $10 \%$ of the total injected cement when the cement viscosity increased from low to medium. Leakage ceased completely when the cement reached high viscosity of a dough-like consistency. However, the standard syringe and cannula used in vertebroplasty or BKP could not inject such a highly viscous cement. Recently, a highviscosity cement and delivery system were developed for vertebral augmentation, using a hydraulic cement injection technique to inject high-viscosity cement into the compressed vertebrae. Retrospective studies indicated that vertebral augmentation by using highviscosity cement may have a role in decreasing the risk of cement leakage and may result in leakage rates lower than vertebroplasty and comparable with that of $\operatorname{BKP}(4,5)$.

Our prospective clinical trial was performed to compare the safety and efficacy of high-viscosity cement vertebroplasty (HVCV) with that of BKP for the treatment of OVCFs in terms of pain, functional capacity, cement leakage, and height restoration.

\section{Methods}

\section{Study Design}

This study was designed as a single-center prospective comparison between HVCV and BKP for treating OVCFs. The study protocol was approved by the local ethics committee. Written consent was obtained from each patient before enrollment. The study was initiated on January 1, 2012, and completed on February 12, 2014, when the final patient completed the one-year postprocedural follow-up.

Magnetic resonance imaging (MRI), thin slice computerized tomography (CT), dual-energy X-ray absorptiometry (DEXA), and anteroposterior (A/P) and lateral radiographs were evaluated before the surgery to determine the appropriateness of the procedure and plan the treated levels. The inclusion criteria were recent lumber or thoracic vertebral compression fractures (proven by radiographs and MRI) and unsatisfactory pain relief (visual analog scale [VAS] $\geq 5$ ) after at least 4-week conventional therapy, and a confirmed diagnosis of osteoporosis or osteopenia (proven by DEXA). Exclusion criteria included burst fractures, infection, radicular syndrome, primary bone tumors, and spinal metastases.

Patients randomly underwent either HVCV (Confidence Spinal Cement System, DePuy Spine Inc, Raynham, MA, USA) or BKP (Kyphon, Sunnyvale, CA, USA). A low-viscosity cement was used, OSTEOPAL V (Heraeus Medical GmbH, Wehrheim, Germany). Patients were blinded to which group they were assigned.

\section{Procedural Technique}

The procedures of HVCV and BKP have been well described previously (4-7). As the unipedicular procedure is safe and effective, and there is no evidence to support the superiority of bipedicular procedures (810), we adopted a unipedicular approach in all patients in this study. Injected cement volume was recorded. The end point of cement injection for both techniques was the presence of radiologically adequate filling, the start of leakage, and/or significantly increased pressure during injection. After the procedure all patients remained supine in bed for 24 hours, and were referred for treatment with calcium and vitamin $D$ supplements, and antiresorptive or anabolic agents.

\section{Data Collection}

Pain scores were recorded using VAS before the procedure, and at one day, 3 months, one year after the procedure. The Oswestry Disability Index (ODI) was compiled to measure patients' functional disability before the procedure and at 3 months and one year after the procedure.

Assessment of cement leakage was based on radiographs, supplemented by postoperative CT scans. In 
addition, the location of leakage was classified as the following (11):

1) disc space,

2) epidural space,

3) paravertebral areas, and

4) peripheral veins.

Changes of the anterior vertebral body height preoperatively, postoperatively, and at one year were calculated on lateral radiographs. The expected prefracture height (predicted height) was the anterior height of healthy vertebrae (cephalad or caudad) that were adjacent to the treated level. The compression rate was calculated using percentage (predicted height - preoperative anterior height)/predicted height. The height of restoration rate was calculated using percentage (postoperative fracture height-preoperative fracture height/ [100-preoperative fracture height]) $(12,13)$. Blinded data about cement leakage and vertebral body height were collected by radiologists.

During the follow-up, any patient who suffered from another new compression fracture was excluded from the assessment of VAS and ODI scores, and any patient who was lost to follow-up was excluded from the assessment of VAS, ODI scores, and vertebral body height.

\section{Statistical Analysis}

The results were summarized with mean values and standard deviations (SD). Wilcoxon rank sum test was used to evaluate differences in VAS and ODI scores in each group. Chi-square test was used to evaluate the difference in cement leakage rates between the 2 groups. Continuous values (injected cement volume, compression rates, and height restoration rates) were analyzed between the 2 groups by using the Student t-test. The $P$ value of less than 0.05 was considered to indicate a statistically significant difference. Statistical analyses were conducted using SAS software version 9.2 (SAS Institute, Cary, NC).

\section{Results}

\section{Demographics}

One hundred seven patients underwent VAPs on 140 compressed vertebral bodies. The summary of patients' demographics is shown in Table 1 . The recruitment and participation process is shown in Fig. 1. Levels treated included T5 to L5. The distribution of levels is shown in Fig. 2. There were no statistically significant
Table 1. Summary of patients' demographics.

\begin{tabular}{|c|c|c|}
\hline & Group HVCV & Group BKP \\
\hline \multicolumn{3}{|l|}{ No. of patients } \\
\hline Enrolled & 53 & 54 \\
\hline 3-month follow-up & $53(100 \%)$ & $52(96.30 \%)$ \\
\hline 1-year follow-up & $50(94.34 \%)$ & $51(94.44 \%)$ \\
\hline No. of treated levels & 68 & 72 \\
\hline Gender (Males/Females) & $12 / 41$ & $14 / 40$ \\
\hline \multicolumn{3}{|l|}{ Age (yr) } \\
\hline Mean \pm SD & $69.43 \pm 8.94$ & $68.63 \pm 8.39$ \\
\hline Range & $52-89$ & $52-90$ \\
\hline VAS $($ Mean \pm SD) & $8.10 \pm 1.23$ & $8.04 \pm 1.13$ \\
\hline ODI scores $($ Mean $\pm \mathrm{SD})$ & $71.22 \pm 10.56$ & $71.30 \pm 10.22$ \\
\hline Compression rate $($ Mean \pm SD) & $29.98 \pm 18.12$ & $28.67 \pm 19.31$ \\
\hline
\end{tabular}

differences between the 2 groups in terms of age, gender, VAS, ODI scores, and compression rate before surgery $(P>0.05)$.

\section{Clinical Assessment}

Both groups experienced significant pain relief and life quality improvement. In the HVCV group, the mean VAS decreased from $8.10 \pm 1.23$ preoperatively to $2.59 \pm 0.76$ on the first day postoperatively $(P<$ $0.05)$, and even further to $1.24 \pm 0.72$ at 3 months and $1.24 \pm 0.95$ at one year $(P<0.05)$, and the respective VAS score for the BKP group was $8.04 \pm 1.13$ preoperatively to $2.54 \pm 0.81$ on the first day postoperatively $(P$ $<0.05)$, and even further to $1.06 \pm 0.68$ at 3 months and $1.02 \pm 0.80$ at one year $(P<0.05)$. The mean ODI score of $71.22 \pm 10.56 \%$ before the procedure dropped to $19.74 \pm 6.44 \%$ at 3 months and $17.04 \pm 6.43 \%$ at one year $(P<0.05)$ after the procedure in the HVCV group, and from $71.30 \pm 10.22 \%$ preoperatively to $19.18 \pm 5.89 \%$ postoperatively at 3 months and 16.20 $\pm 6.70 \%$ at one year $(P<0.05)$ in the BKP group. The VAS and ODI scores didn't change significantly after 3 months postoperatively. There were no statistically significant differences between the 2 groups in terms of VAS and ODI scores at the above mentioned times of assessment (Table 2).

\section{Radiological Assessment}

The mean injected cement volume was $3.31 \pm 0.77$ $\mathrm{mL}$ (range, $1.5-5 \mathrm{~mL}$ ) in the HVCV group, which was significantly different from the mean injected cement volume of $4.22 \pm 1.29 \mathrm{~mL}$ (range, $1.7-6.8 \mathrm{~mL}$ ) in the BKP goup $(P<0.0001)$.

Leakage rates and the location are presented in 


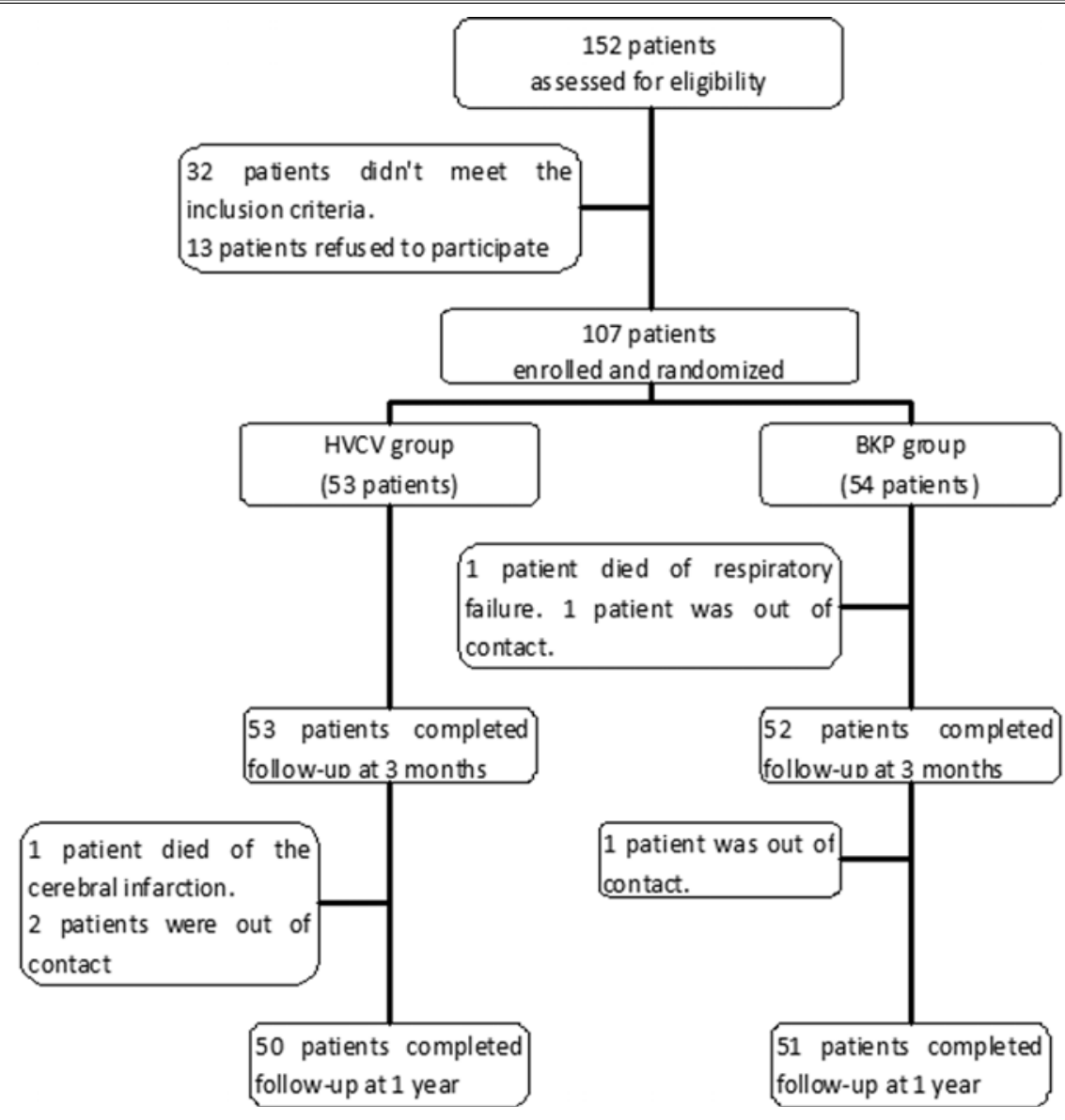

Fig. 1. Diagram of recruitment and participation process.

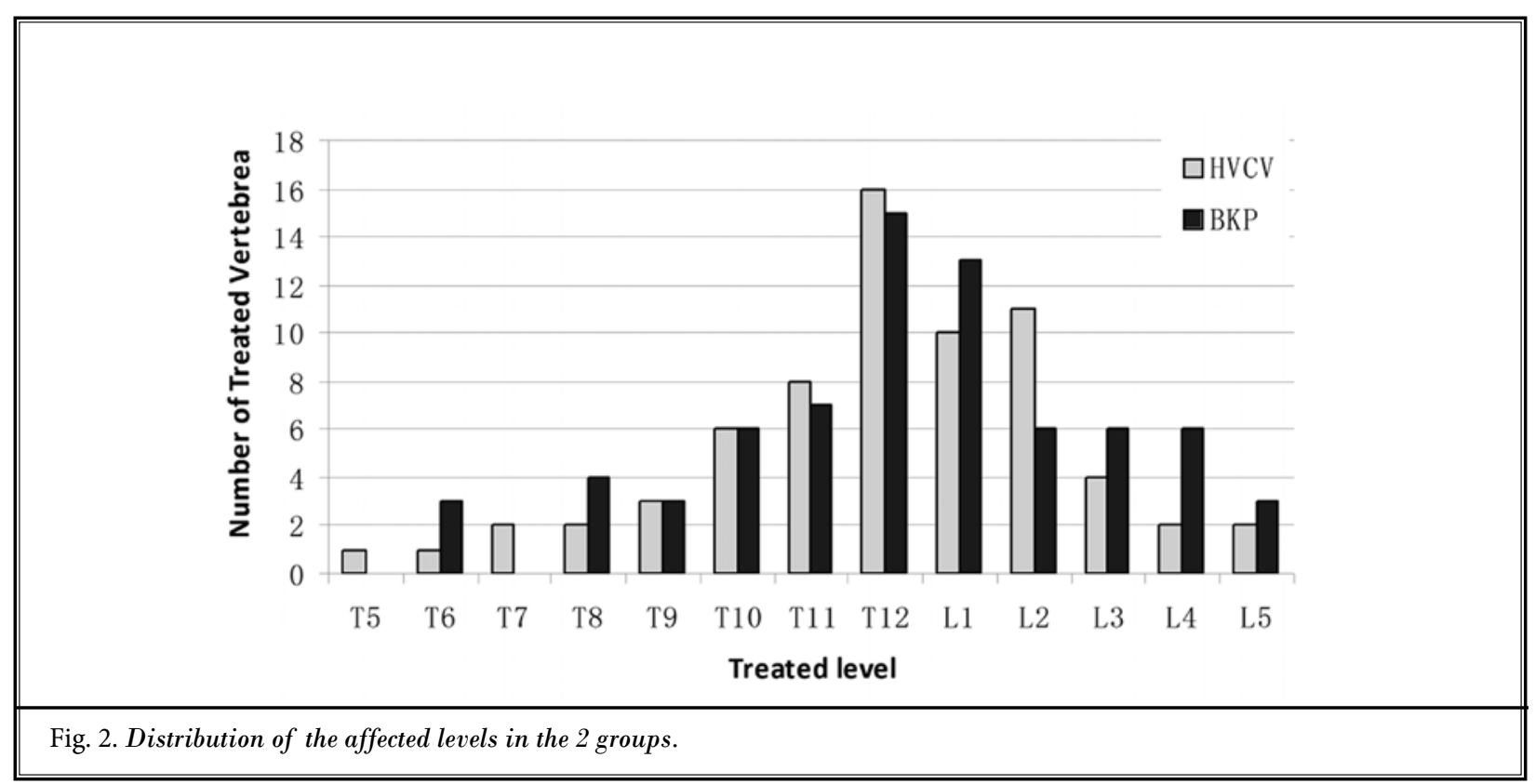


Table 2. Overview of VAS and ODI scores in the 2 groups.

\begin{tabular}{|c|c|c|c|c|}
\hline \multirow{2}{*}{ Group } & \multicolumn{4}{|c|}{ VAS } \\
\hline & Preoperatively & Postoperatively & 3 months & 12 months \\
\hline $\mathrm{HVCV}$ & $8.10 \pm 1.23$ & $2.59 \pm 0.76^{*}$ & $1.24 \pm 0.72 \#$ & $1.24 \pm 0.95 \#$ \\
\hline BKP & $8.04 \pm 1.13$ & $2.54 \pm 0.81^{\star}$ & $1.06 \pm 0.68 \#$ & $1.02 \pm 0.80 \#$ \\
\hline \multirow{2}{*}{ Group } & \multicolumn{4}{|c|}{ ODI (\%) } \\
\hline & Preoperatively & \multicolumn{2}{|c|}{ Postoperative 3 months } & 12 months \\
\hline HVCV & $71.22 \pm 10.56$ & \multicolumn{2}{|c|}{$19.74 \pm 6.44^{*}$} & $17.04 \pm 6.43 \#$ \\
\hline ВКР & $71.30 \pm 10.22$ & \multicolumn{2}{|c|}{$19.18 \pm 5.89^{*}$} & $16.20 \pm 6.70 \#$ \\
\hline
\end{tabular}

Data are expressed as mean $\pm \mathrm{SD} .{ }^{*}$ significant difference with other values $(P<0.05)$ \# significant difference with other values $(P<0.05)$

Table 3. Cement leakages in the 2 groups.

\begin{tabular}{|c|c|c|c|c|c||}
\hline \multirow{2}{*}{ Group } & \multirow{2}{*}{ Leakages } & \multicolumn{4}{|c||}{ Location of Leakages $^{\#}$} \\
\cline { 3 - 6 } & & Disc Space & Epidural Space & Paravertebral Area & Peripheral Vein \\
\hline HVCV & $9 / 68(13.24 \%)^{*}$ & $3(33.33 \%)^{*}$ & $2(22.22 \%)$ & $3(33.33 \%)$ & $1(1.11 \%)$ \\
\hline BKP & $22 / 72(30.56 \%)$ & $11(47.83 \%)$ & $6(26.09 \%)$ & $4(17.39 \%)$ & $2(8.70 \%)$ \\
\hline
\end{tabular}

"In the BKP group, one level had multiple leaks (epidural space and peripheral vein). ${ }^{*}$ significant difference with BKP group $(P<0.05)$

Table 3. The cement leakage rate was $13.24 \%$ in the HVCV group, which was lower than the $30.56 \%$ in the BKP group $(P<0.05)$. The cement leakage was observed most commonly into the disc space.

The mean preoperative compression rate was 29.98 $\pm 18.12 \%$ in the HVCV group and $28.67 \pm 19.31 \%$ in the BKP group $(P=0.94)$. The mean vertebral height restoration rate was $30.04 \pm 17.38 \%$ in the HVCV group and $42.65 \pm 20.11 \%$ in the BKP group. The differences were statistically significant between 2 groups $(P<0.0001)$. At one year follow-up, there was no significant loss of height to be noted for each group $(P>0.05)$.

\section{Complications and New Fractures}

No symptomatic cement leakage, neurological deficit, or embolism occurred in the HVCV group. In the BKP group, one patient experienced severe discogenic back pain related to a disc leak and finally underwent discetomy with posterior spinal fusion (Fig. 3). The second complication in this group was asymptomatic cement emboli in the right lung related to venous leakage (Fig. 4). No mortalities or infections were observed in the 2 groups.

There was one case of a new adjacent vertebral fracture in the HVCV group (2\%), and 4 cases of new nonadjacent vertebral fractures in the BKP group $(7.84 \%)$. Subsequent fractures were not statistically different between the 2 groups $(P=0.18)$. All new fractures were treated surgically.

\section{Discussion}

Good clinical outcomes have been previously reported for BKP and HVCV in the treatment of painful OVCFs $(4,5,11,12)$. In our study, as in other studies, both BKP and HVCV achieved satisfactory clinical outcomes, providing pain relief and improvement in the quality of life after surgery. There was no difference between the 2 procedures. HCVC can alleviate the need for balloon and cavity creation within the vertebral body, thus significantly reducing the number of steps and procedure time.

The major complications arising from vertebral augmentation are related to cement leakage. Although most leaks are clinically asymptomatic, they could increase the risk of neurological complications and pulmonary embolism (12,14-16). Cement leakage rates reported in the literatures are variable, ranging from $9 \%$ to $72 \%$ for vertebroplasty and $7 \%$ to $59 \%$ for BKP $(4,13,17,18)$. As shown in a meta-analysis, leakage rate ranges from $18.1 \%$ for BKP to $41.1 \%$ for vertebroplasty (19). Our results demonstrated a leakage rate of $30.56 \%$ for BKP. Besides cavity creation in BKP that allows for low-pressure controlled cement filling, cement viscosity plays a pivotal role (2). In a retrospective study, Georgy (4) observed a leakage rate of $47 \%$ for high-viscosity cement, with no difference from BKP (59\%). In another randomized trial, HVCV was found to have significantly lower leakage rates $(8.2 \%)$ than vertebroplasty with a 

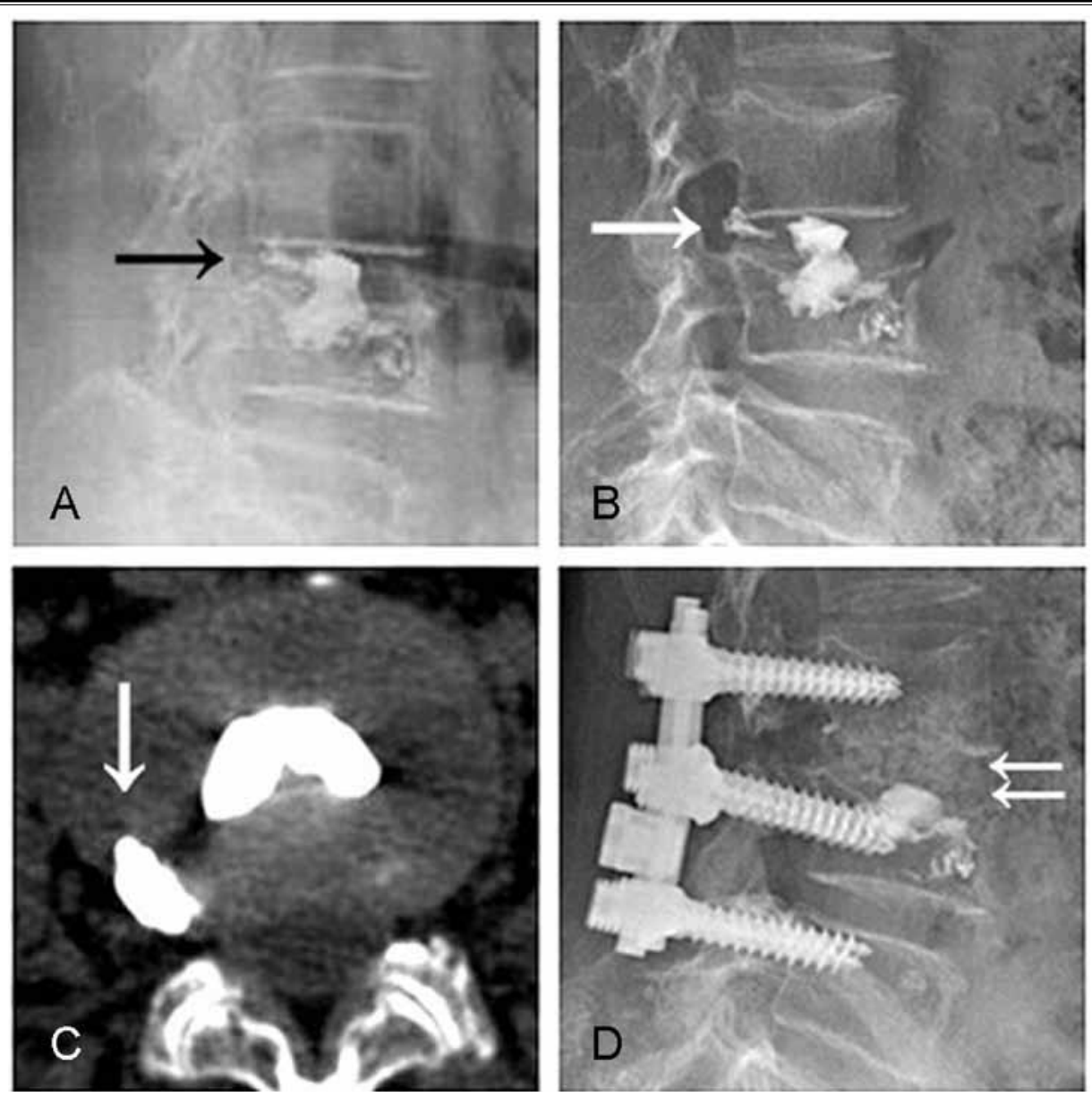

Fig. 3. Images from a 72-year-old woman who underwent BKP. Cement leakege (arrow) into L3-4 disc is demonstrated on the plain film (A). The leaked cement (white arrow) migrated posteriorly to the posterior annulus fibrous on the plain film (B). Axial CT image shows the cement (white arrow) is adjacent to the posterior annulus fibrous (C). The discetomy with posterior spinal fusion were subsequently performed because of severe discogenic back pain. Postoperative lateral lumbar plain film (D) confirms the removal of leaked cement from L3-4 disc (duble white arrow).
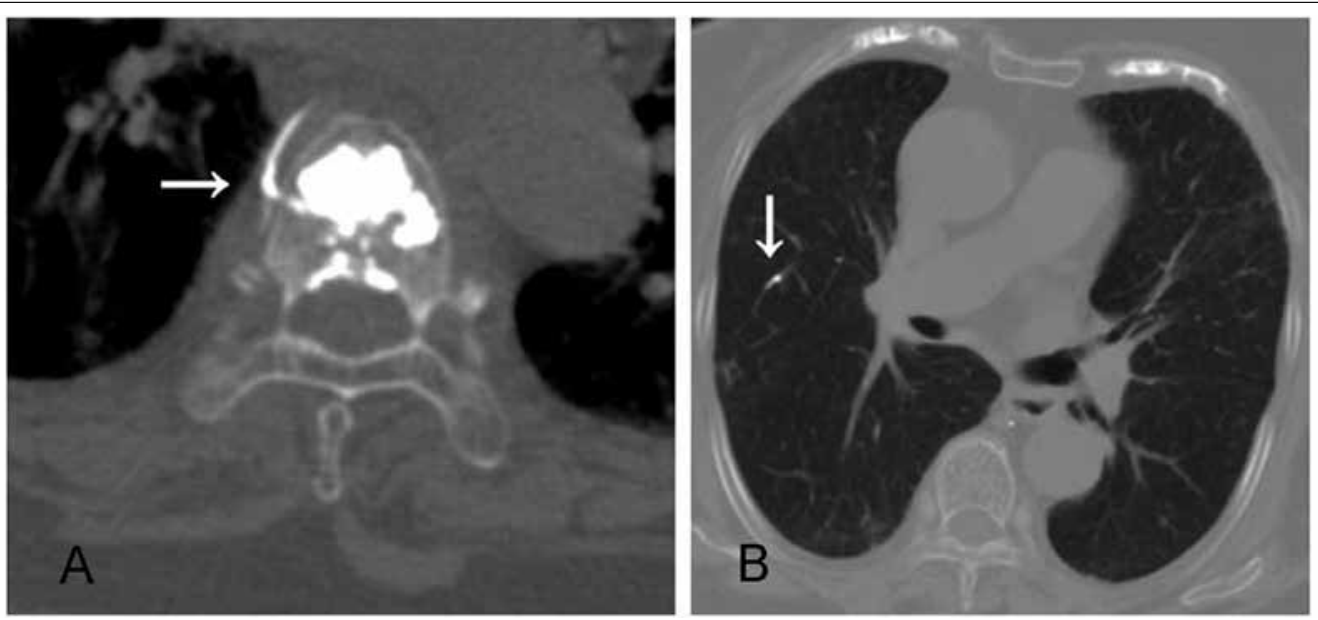

Fig. 4. Another patient from Group BKP. Axial CT images show cement leakage (white arrow) into peripheral vein (A) and cement emboli (white arrow) of the right lung $(B)$, respectively. 
standard low-viscosity cement (41.3\%) (5). In our study, the cement leakage rate for HVCV was $13.24 \%$, which was lower than the $30.56 \%$ for BKP. Compared with BKP, our results showed that HVCV not only reduced the overall leakage rates, but also significantly reduced the rate of leakages into the disc. In OVCFs, leakage into the disc space commonly occurs through an intravertebral vacuum cleft or through a perforation of the endplate (20). Besides the usage of high-viscosity cement, HVCV uses a needle with a beveled end, which can be turned toward the center of the vertebral body, thereby providing some degree of directionality to the cement flow which could reduce the incidence of disc leaks. In our study, leakage into the epidural space was detected in $2.94 \%(2 / 68)$ of treated vertebrae for HVCV and $7.89 \%$ (6/72) for BKP, and all were without neurological complications. There was no significant difference between the 2 groups, although we did recognize the lower propensity for epidural space leakage in the HVCV group.

Subsequent fractures occurred in $2 \%$ of HVCV cases and $7.84 \%$ of BKP cases; however, the difference was not statistically significant. This is in accordance with previous studies showing no difference between VAPs in terms of subsequent fractures $(14,19)$. The disc leakage has been considered to increase the risk of subsequent adjacent vertebral fractures (20-22), but this is not a consistent finding (23). In our study, one patient in the HVCV group and 4 patients in the BKP group with a new vertebral fracture did not show any leak into the disc during the first treatment.

One patient incurred a disc leakage during the BKP procedure. Cement migration into the disc was observed moving posteriorly to the posterior annulus fibrous, which led to severe discogenic back pain. After failing to respond to 6 weeks of conventional therapy, the patient finally underwent discetomy with posterior spinal fusion (Fig. 3). We found no reports discussing discogenic back pain as a result of disc leakage, as shown in our study.

BKP has been reported to obtain significant height restoration and/or kyphosis reduction $(12,13,24,25)$, with the height restoration rates for a unipedicular procdure varying from $24.25 \%$ to $48.9 \%$. In keeping with these studies, our results showed BKP gained $42.67 \%$ height restoration. HVCV was reported to be effective in terms of vertebral height restoration. The mechanism of restoration is considered as postural reduction (i.e., laying the patient in a prone over-extended position) (6). In our study, although HVCV also achieved significant vertebral height restoration, the percentage of restoration remained less than that of BKP. The restoring mechanism of BKP can be explained by the postural reduction and by the additional inflating effect of the balloon. To our knowledge, no studies have compared HVCV with BKP in respect to height restoration. The addition of endplate elevation with balloon inflation gives BKP a distinct advantage. Ironically, there was no statistical difference between the 2 groups with regard to VAS and ODI scores postoperatively. If theoretically, height restoration leads to improvement in spinal alignment, thereby reducing flexion stresses at and surrounding the affected vertebrae resulting in relaxation of the paraspinal muscles, this should lead to a more upright posture and reduction in pain (17). Perhaps the vertebral height restoration for BKP does not change the general sagittal balance of the spine significantly enough to produce a statistically significant difference in patients' VAS and ODI scores. This will require further research.

In recent years, a novel vertebral augmentation method, combining the advantages of both HVCV and $B K P$, has been introduced. Radiofrequency-targeted vertebral augmentation (RF-TVA) creates a cavity in the vertebral body using a flexible osteotome, followed by delivering an ultra-high viscosity cement that is activated by a radiofrequency unit into the cavity through a unique hydraulic delivery system (26). Studies have shown that RF-TVA can reduce the risk of cement leakage and achieve favorable vertebral height restoration $(11,27)$.

\section{Limitations}

Our study was a single-center study with a relatively small sample size, and therefore may not fully reflect interoperator variablity. Additional multicenter, largerscale studies would solve this issue. We did not distinguish between dynamic fractures or fixed fractures. Dynamic fractures, with intravertebral cleft identification, can achieve greater height restoration (28). To more effectively evaluate height restoration, our future research will compare the effects of vertebral augmentation relative to height restoration in these 2 fracture types.

\section{Conclusion}

HVCV and BKP are safe and effective in improving the quality of life and relieving pain. HVCV has a lower cement leakage rate. For its increasing the safety of vertebroplasty techniques and reducing the number of steps and procedure time, HVCV is recommended for the treatment of OVCFs. BKP is more effective in vertebral height restoration. Subsequent fractures are not different between the 2 groups. 


\section{References}

1. Ma XL, Xing D, Ma JX, Xu WG, Wang J, Chen Y. Balloon kyphoplasty versus percutaneous vertebroplasty in treating osteoporotic vertebral compression fracture: Grading the evidence through a systematic review and meta-analysis. Eur Spine J 2012; 21:1844-1859.

2. Bohner M, Gasser B, Baroud G, Heini $P$. Theoretical and experimental model to describe the injection of a polymethylmethacrylate cement into a porous structure. Biomaterials 2003; 24:2721-2730.

3. Baroud G, Crookshank M, Bohner M. High-viscosity cement significantly enhances uniformity of cement filling in vertebroplasty: An experimental model and study on cement leakage. Spine 2006; 31:2562-2688.

4. Georgy BA. Clinical experience with high-viscosity cements for percutaneous vertebral body augmentation: Occurrence, degree, and location of cement leakage compared with kyphoplasty. AJNR Am J Neuroradiol 2010; 31:504-508.

5. Anselmetti GC, Zoarski G, Manca A, Masala S, Eminefendic H, Russo F, Regge D. Percutaneous vertebroplasty and bone cement leakage: Clinical experience with a new high-viscosity bone cement and delivery system for vertebral augmentation in benign and malignant compression fractures. Cardiovasc Intervent Radiol 2008; 31:937-947.

6. Folman Y, Shabat S. A comparison of two new technologies for percutaneous vertebral augmentation: Confidence vertebroplasty vs. sky kyphoplasty. Isr Med Assoc J 2011; 13:394-397.

7. Lee SB, Cho KS, Huh PW, Yoo DS, Kang SG, Kim DS, Park CK. Clinical and radiographic results of unilateral transpedicular balloon kyphoplasty for the treatment of osteoporotic vertebral compression fractures. Acta Neurochir Suppl 2008; 101:157-160.

8. Steinmann J, Tingey CT, Cruz G, Dai Q. Biomechanical comparison of unipedicular versus bipedicular kyphoplasty. Spine 2005; 30:201-205.

9. Wang Z, Wang G, Yang H. Comparison of unilateral versus bilateral balloon kyphoplasty for the treatment of osteoporotic vertebral compression fractures. J Clin Neurosci 2012; 19:723-726.

10. Li LH, Sun TS, Liu Z, Zhang JZ, Zhang $\mathrm{Y}$, Cai YH, Wang H. Comparison of uni- pedicular and bipedicular percutaneous kyphoplasty for treating osteoporotic vertebral compression fractures: A meta-analysis. Chin Med J (Engl) 2013; 126:3956-3961.

11. Georgy BA. Comparison between radiofrequency targeted vertebral augmentation and balloon kyphoplasty in the treatment of vertebral compression fractures: Addressing factors that affect cement extravasation and distribution. Pain Physician 2013; 16:E513-E518.

12. Majd ME, Farley S, Holt RT. Preliminary outcomes and efficacy of the first 360 consecutive kyphoplasties for the treatment of painful osteoporotic vertebral compression fractures. Spine J 2005; 5:244-255.

13. Bozkurt M, Kahilogullari G, Ozdemir M, Ozgural O, Attar A, Caglar S, Ates C. Comparative analysis of vertebroplasty and kyphoplasty for osteoporotic vertebral compression fractures. Asian Spine ] 2014; 8:27-34.

14. Röllinghoff $M$, Siewe J, Zarghooni K, Sobottke R, Alparslan Y, Eysel P, Delank KS. Effectiveness, security and height restoration on fresh compression fractures - a comparative prospective study of vertebroplasty and kyphoplasty. Minim Invasive Neurosurg 2009; 52:233-237.

15. Duran C, Sirvanci M, Aydogan M, Ozturk E, Ozturk C, Akman C. Pulmonary cement embolism: A complication of percutaneous vertebroplasty. Acta Radiol 2007; 8:854-859.

16. Padovani B, Kasriel O, Brunner P, PerettiViton P. Pulmonary embolism caused by acrylic cement: A rare complication of percutaneous vertebroplasty. Am J Neuroradiol 1999; 20:375-377.

17. Klazen CA, Venmans A, de Vries J, van Rooij WJ, Jansen FH, Blonk MC, Lohle PN, Juttmann JR, Buskens E, van Everdingen $\mathrm{KJ}$, Muller A, Fransen $\mathrm{H}$, Elgersma OE, Mali WP, Verhaar HJ. Percutaneous vertebroplasty is not a risk factor for new osteoporotic compression fractures: Results from VERTOS II. AJNR Am J Neuroradiol 2010; 31:1447-1450.

18. Eck JC, Nachtigall D, Humphreys SC Hodges SD. Comparison of vertebroplasty and balloon kyphoplasty for treatment of vertebral compression fractures: A meta-analysis of the literature. Spine ] 2008; 8:488-497.

19. Papanastassiou ID, Phillips FM, Van
Meirhaeghe J, Berenson JR, Andersson GB, Chung G, Small BJ, Aghayev $\mathrm{K}$, Vrionis FD. Comparing effects of kyphoplasty, vertebroplasty, and nonsurgical management in a systematic review of randomized and non-randomized controlled studies. Eur Spine J 2012; 21:1826-1843.

20. Chen WJ, Kao YH, Yang SC, Yu SW, Tu YK, Chung KC. Impact of cement leakage into disks on the development of adjacent vertebral compression fractures. J Spinal Disord Tech 2010; 23:33-39.

21. Ahn Y, Lee JH, Lee HY, Lee SH, Keem $\mathrm{SH}$. Predictive factors for subsequent vertebral fracture after percutaneous vertebroplasty. J Neurosurg Spine 2008; 9:129-136.

22. Lin EP, Ekholm S, Hiwatashi A, Westesson PL. Vertebroplasty: Cement leakage into the disc increases the risk of new fracture of adjacent vertebral body. AJNR Am J Neuroradiol 2004; 25:175-180.

23. Syed MI, Patel NA, Jan S, Harron MS, Morar K, Shaikh A. Intradiskal extravasation with low volume cement filling in percutaneous vertebroplasty. Am J Neuroradiol 2005; 26:2397-2401.

24. Chen C, Chen L, Gu Y, Xu Y, Liu Y, Bai X, Zhu X, Yang H. Kyphoplasty for chronic painful osteoporotic vertebral compression fractures via unipedicular versus bipedicular approachment: A comparative study in early stage. Injury 2010; 41:356-359.

25. Papadopoulos EC, Edobor-Osula F, Gardner MJ, Shindle MK, Lane JM. Unipedicular balloon kyphoplasty for the treatment of osteoporotic vertebral compression fractures: Early results. J Spinal Disord Tech 2008; 21:589-596.

26. Robertson SC. Percutaneous vertebral augmentation: StabilitiT a new delivery system for vertebral fractures. Acta Neurochir Suppl 2011; 108:191-195.

27. Dalton BE, Kohm AC, Miller LE, Block JE, Poser RD. Radiofrequency-targeted vertebral augmentation versus traditional balloon kyphoplasty: Radiographic and morphologic outcomes of an ex vivo biomechanical pilot study. Clin Interv Aging 2012; 7:525-531.

28. McKiernan F, Jensen R, Faciszewski T. The dynamic mobility of vertebral compression fractures. J Bone Miner Res 2003; 18:24-29. 